\title{
PTEN inactivation in lung cancer cells and the effect of its recovery on treatment with epidermal growth factor receptor tyrosine kinase inhibitors
}

\author{
RINTARO NORO, AKIHIKO GEMMA, AKIHIKO MIYANAGA, SEIJI KOSAIHIRA, YUJI MINEGISHI, \\ MICHIYA NARA, YUTAKA KOKUBO, MASAHIRO SEIKE, KIYOKO KATAOKA, \\ KUNIKO MATSUDA, TETSUYA OKANO, AKINOBU YOSHIMURA and SHOJI KUDOH
}

Department of Pulmonary Medicine/Infection and Oncology, Nippon Medical School, 1-1-5 Sendagi, Bunkyo-ku, Tokyo 113-8602, Japan

Received June 14, 2007; Accepted August 2, 2007

\begin{abstract}
To understand the mechanisms of PTEN inactivation, which is reported to be involved in tumor progression and drug resistance in lung cancer, we analyzed the expression levels of PTEN at mRNA and protein levels, along with the genetic and epigenetic status of the PTEN gene, in a panel of lung cancer cell lines. Western blot analysis showed that six out of $25(24 \%)$ cell lines displayed low expression of PTEN protein. The level of PTEN mRNA correlated well with corresponding protein expression in each of these six cell lines. In two of the six cell lines genomic analysis revealed homozygous deletions of the PTEN gene. Another two of the six cell lines displayed hypermethylation of the PTEN gene promoter assessed by methylation-specific PCR. The levels of PTEN mRNA and protein expression in PC9/f9 and PC9/f14 cells, which are gefitinib-resistant derivatives of the gefitinib-sensitive cell line, PC9, were reduced compared to the parental line. After treatment with the demethylating agent 5-aza-2'deoxycytidine (5-AZA) and the histone deacetyltransferase (HDAC) inhibitor Trichostatin A (TSA), the expression levels of PTEN mRNA and protein in these four cell lines (PC9/f9, PC9/f14, PC10 and PC14) were actually restored. In summary, reduction in PTEN protein expression was regulated by histone deacetylation and hypermethylation of the gene promoter, as well as homozygous deletion. In addition, we demonstrated that the combination treatment of gefitinib and TSA induced significant growth inhibition in gefitinib-resistant PC9/f9 and PC9/f14 cells. These findings suggest that the combination of the epidermal growth factor receptor tyrosine kinase inhibitor gefitinib with the demethy-
\end{abstract}

Correspondence to: Dr Akihiko Gemma, Department of Pulmonary Medicine/Infection and Oncology, Nippon Medical School, 1-1-5 Sendagi, Bunkyo-ku, Tokyo 113-8602, Japan

E-mail: agemma@nms.ac.jp

Key words: PTEN, lung cancer, homozygous deletion, promoter hypermethylation, histone deacethylase inhibitor lating agent 5-AZA and the HDAC inhibitor TSA may be a useful strategy for the treatment of some lung cancers.

\section{Introduction}

Lung cancer is one of the leading causes of cancer mortality in both men and women and its incidence is increasing worldwide (1). The 5-year survival rate of lung cancer patients is only $15 \%$ and this situation has not remarkably improved over the last 30 years. Improving survival rate of patients with this disease requires a better understanding of tumor biology and the subsequent development of novel therapeutic strategies.

PTEN is a tumor-suppressor gene located on chromosomal position 10q23.3 (2). PTEN is a lipid phosphatase that acts by dephosphorylating the 3-position of phosphatidylinositol 3,4,5-triphosphate, a second messenger of PI3K $(3,4)$. PTEN antagonizes PI3K activity and negatively regulates its downstream target, the serine/threonine kinase Akt, which is a cytosolic signal transduction protein implicated in carcinogenesis and chemoresistance $(5,6)$. According to recent reports, loss of PTEN is associated with poor prognosis for lung cancer patients (7-9), as well as resistance towards many anti-cancer agents, including gefitinib, an epidermal growth factor receptor tyrosine kinase inhibitor (10-12).

Alterations of the PTEN gene have been demonstrated in 8-16\% of examined non-small cell lung cancer (NSCLC) cell lines suggesting that PTEN is infrequently targeted in NSCLC tumorigenesis. Studies of PTEN in NSCLC have focused exclusively on searching for mutations or deletions of the gene, with little emphasis on examining alterations at the protein level (13-16). DNA hypermethylation as a mechanism for PTEN inactivation has been reported in the context of lung carcinomas (17). Soria et al found that $24 \%$ of the lung cancers tested showed a lack of staining for PTEN protein expression, although PTEN methylation was detected in only $35 \%$ of the PTEN-negative NSCLC samples using methylation-specific PCR (17). Other mechanisms, that have yet to be developed, are required to explain the basis of reduced PTEN protein expression in lung cancer. It also remains unknown whether the expression of PTEN mRNA and protein expression in these cells can be restored after treatment with the demethylating agent, 5-aza-2'deoxycytidine 
(5-AZA). In an effort to clarify these issues, we took a panel of lung cancer cell lines and examined the levels of PTEN protein expression using Western blot analysis and determined the genetic and epigenetic status of the PTEN gene. We also attempted to recover PTEN protein expression in a subset of lung cancer cell lines by exposure to 5-AZA and the histone deacetyltransferase (HDAC) inhibitor, Trichostatin A (TSA). We also investigated the recovery of the antitumor activity of gefitinib by the recruitment of PTEN expression via TSA in gefitinib-resistant sublines of PC9 cells.

\section{Materials and methods}

Cell lines. Twelve adenocarcinoma cell lines (ABC-1, A549, PC3, PC7, RERF-LCMS, RERF-LCKJ, VMRC-LCD, RERFLCOK, PC14, PC9, PC9/f9 and PC9/f14), eight squamouscell carcinoma cell lines (QG56, EBC-1, LK-2, LC-1/sq, PC1, RERF-LCAI, PC10 and SQ5), five small-cell carcinoma cell lines (NCI-H69, SBC3, NCI-N231, Lu135 and MS-1), as well as an immortalized tracheal cell line (BET2A), were subjected to PTEN gene mutational analysis and mRNA and protein expression analysis. The Lu135 cell line was provided by Y. Shimosato and T. Terasaki (National Cancer Center Research Institute, Tokyo, Japan). The LCD and LCOK cell lines were provided by S. Hirohashi (National Cancer Center Research Institute, Tokyo, Japan). The NCIN231, A549, NCI-H69 and BET2A cell lines were obtained from the American Type Culture Collection (Rockville, MD) $(18,19)$. The PC1, PC3, PC7, PC9, PC10, PC14 and QG-56 cell lines were obtained from IBL (Gunma, Japan). The RERF-LC-KJ, SQ5, LC-1/Sq, RERF-LCAI, and MS-1 cell lines were obtained from RIKEN Cell Bank (Ibaragi, Japan). The ABC-1, RERF-LC-MS, LK-2, EBC-1, and SBC-3 cell lines were obtained from the Health Science Research Resources Bank (Osaka, Japan). PC9/f9 (20) and PC9/f14 (21) are highly metastatic sublines of PC9 established at Nippon Medical School using artificial metastasis methods.

Western blot analysis. Western blot analysis was performed as previously described (12). The membranes were first incubated overnight at $4^{\circ} \mathrm{C}$ with primary antibodies specific for either PTEN (Santa Cruz Biotechnology, Santa Cruz, CA) or B-actin (all from Cell Signaling Technology, Beverly, MA). The membranes were then incubated with peroxidaseconjugated secondary antibodies, with antibody-antigen complexes detected via an enhanced chemiluminescence (ECL) kit (Amersham, Buckinghamshire, UK) (12).

Polymerase chain reaction-single strand conformation polymorphism (PCR-SSCP) analysis and sequencing of genomic DNA. From each genomic DNA sample, all exons of the PTEN gene were amplified separately using previously described PCR primers (16) via the GeneAmp XL PCR kit (Perkin-Elmer/Roche, Branchburg, NJ, USA). PCR amplification conditions for analysis of genomic DNA were as follows: 40 cycles at $94^{\circ} \mathrm{C}$ for $40 \mathrm{sec}, 60^{\circ} \mathrm{C}$ for $30 \mathrm{sec}$ and $68^{\circ} \mathrm{C}$ for $90 \mathrm{sec}$, followed by $68^{\circ} \mathrm{C}$ for $8 \mathrm{~min}$. Each reaction mixture contained $1 \mathrm{X}$ XL buffer, $200 \mu \mathrm{M}$ deoxynucleotide triphosphate, $1100 \mu \mathrm{M} \mathrm{Mg}(\mathrm{OAc})_{2}, 0.5 \mathrm{U}$ rTth DNA polymerase XL, $0.3 \mathrm{mM}$ of each primer (one of each pair) (16) and $25 \mathrm{ng}$ of genomic DNA. PCR products were loaded onto $1.2 \%$ agarose gels and analyzed following electrophoretic separation. PCR-SSCP and DNA sequence analyses were performed as previously described (22).

Real-time RT-PCR analysis. Real-time quantitative RT-PCR assessment of PTEN gene expression was performed using the ABI PRISM 7700 Sequence Detector system (PerkinElmer/Applied Biosystems, Fosters City, CA). Both the PCR primers and associated TaqMan fluorogenic probe were designed using the Primer Express software program (PerkinElmer/Applied Biosystems). The relevant oligonucleotide sequences were as follows: PTEN: sense, TGGCTAAGTGA AGATGACAATCATG; antisense, TGCACATATCATTAC ACCAGTTCGT; probe, TGCAGCAATTCACTGTAAAGC TGGAAAGG. GAPDH: sense, GAAGGTGAAGGTCGGA GTC; antisense, GAAGATGGTGATGGGATTTC; probe, CAAGCTTCCCGTTCTCAGCC.

Total RNA was extracted from cultured cells and reverse transcribed using the RevaTra Ace Kit, with a random hexamer being used as primer (Toyobo Co., Osaka, Japan). A portion of the resulting cDNA was used for quantitative PCR in a $50-\mu 1$ final volume, together with the desired primers, TaqMan probe, and Master Mix, the latter being composed of PCR buffer, $\mathrm{MgCl}_{2}$, dATP, dCTP, dGTP, dUTP, AmpErase UNG, and AmpliTaq Gold DNA polymerase (Perkin-Elmer/ Applied Biosystems). The initial thermal cycling conditions were $50^{\circ} \mathrm{C}$ for $2 \mathrm{~min}$ and $95^{\circ} \mathrm{C}$ for $10 \mathrm{~min}$, as recommended by the manufacturer, followed by 40 cycles of $95^{\circ} \mathrm{C}$ for $15 \mathrm{sec}$ and $60^{\circ} \mathrm{C}$ for $1 \mathrm{~min}$. The level of the PTEN gene expression was expressed as a ratio of the PTEN mRNA in a particular sample to the level of glyceraldehyde-3-phosphate dehydrogenase (GAPDH) mRNA in that sample. Each sample was measured at least three times $(21,23)$.

Sodium bisulfite modification and methylation-specific PCR (MSP). The methylation status of the promoter region of the PTEN gene was analyzed by methylation-specific PCR (MSP) (24) using the CpG DNA Modification kit (Intergen Company, Purchase, NY) and CpG WIZ Amplification kit (Intergen). Each DNA sample was subjected to bisulfite modification. One $\mu \mathrm{g}$ of DNA was placed in $100 \mu \mathrm{l}$ of water and denatured by adding $7.0 \mu 1$ of $3 \mathrm{M} \mathrm{NaOH}$ for $10 \mathrm{~min}$ at $37^{\circ} \mathrm{C}$. To each denatured DNA solution was added $550 \mu 1$ of freshly prepared sodium bisulfite mixture (Intergen), with these solutions then being incubated at $50^{\circ} \mathrm{C}$ for $16 \mathrm{~h}$. During bisulfite modification, unmethylated cytosines are deaminated and converted to uracils, whereas the 5-methylcytosines remain unaltered. The DNA samples were then purified by ethanol precipitation and resuspended in 25-50 $\mu 1$ of TE (10 mM Tris/0.1 mM EDTA, pH 7.5). PCR amplification was performed with MSP primers (Intergen) that had been designed to distinguish methylated from unmethylated DNA, as follows: PTENM: sense, TTTTTTTTCGGTTTTTCGA GGC; antisense, CAATCGCGTCCCAACGCCG; PTENUM: sense, TTTTGAGGTGTTTGGGTTTTTGGT; antisense, ACACAATCACATCCCAACACCA.

These primers that amplified a specific region of the PTEN promoter (not the PTEN pseudogene) were used, as previously described (25). The PCR reaction mixture consisted of $1 \mathrm{X}$ 


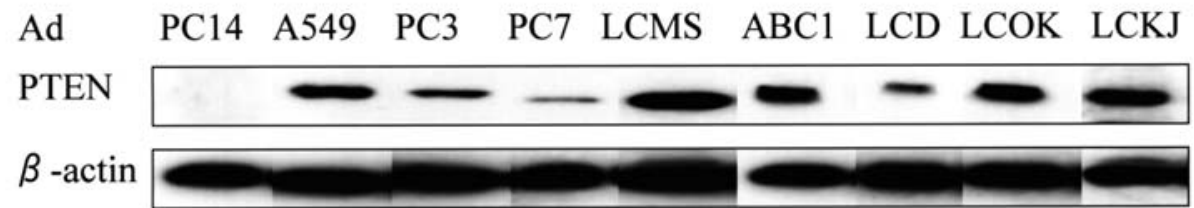

BET2A(normal)
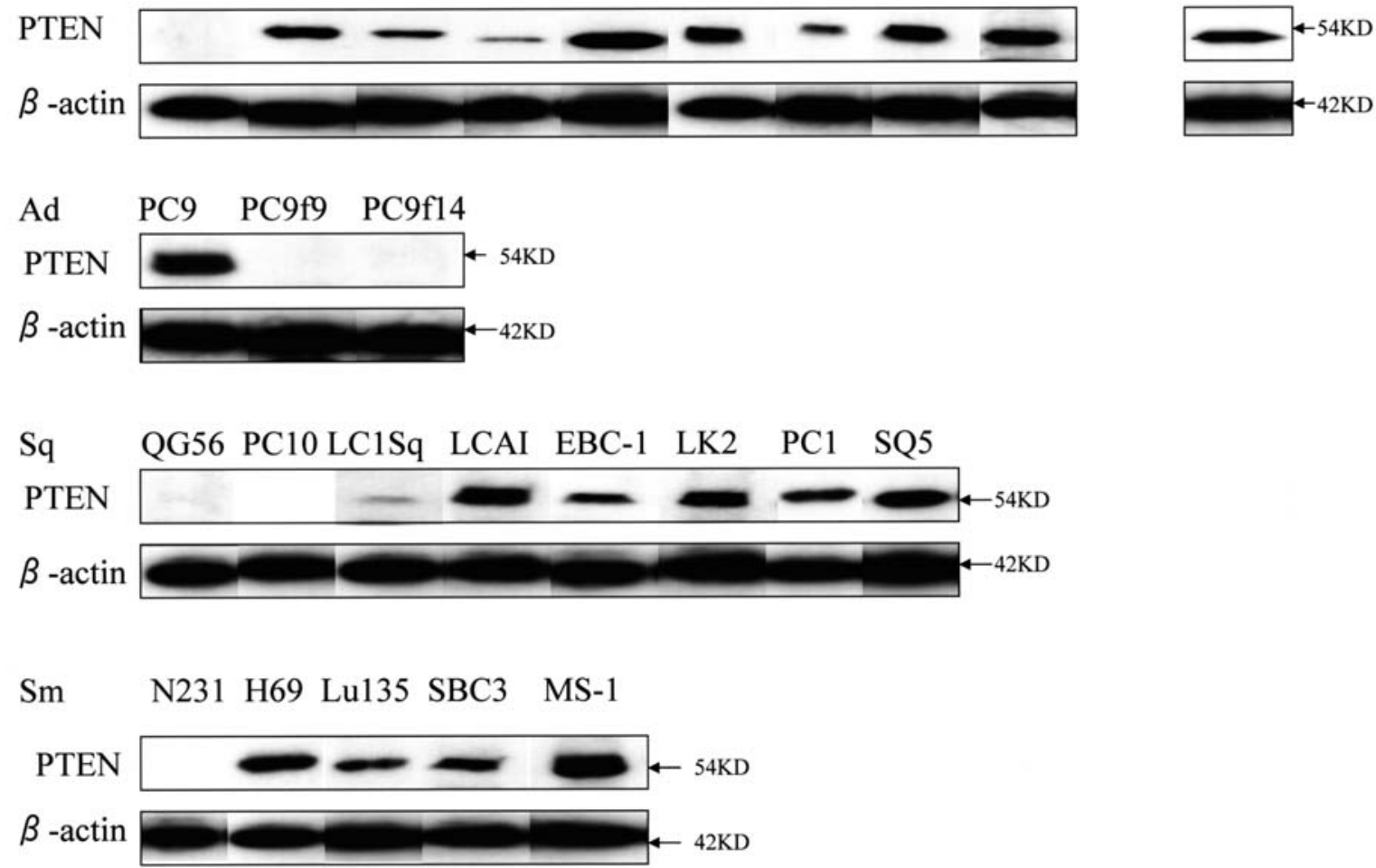

Figure 1. Western blot analysis of PTEN protein expression. The expression levels of PTEN and B-actin protein in all 25 lung cancer cell lines, as well as BET2A cells, was analyzed. Six out of the 25 cell lines $(24 \%)$ showed low PTEN expression. BET2A cells showed moderate PTEN expression. Ad, adenocarcinoma cell lines; Sq, squamous cell carcinoma cell lines; Sm, small cell carcinoma cell lines.

Universal PCR buffer, $250 \mu \mathrm{M}$ deoxynucleotide triphosphate, $0.2 \mu \mathrm{M}$ of each primer, $1.25 \mathrm{U}$ of AmpliTaq Gold, and $2 \mathrm{ng}$ of template DNA in a final volume of $25 \mu \mathrm{l}$. PCR amplification was performed as follows: denaturation at $95^{\circ} \mathrm{C}$ for $12 \mathrm{~min}$, followed by denaturation at $95^{\circ} \mathrm{C}$ for $45 \mathrm{sec}$, annealing at $60^{\circ} \mathrm{C}$ for $45 \mathrm{sec}$, and extension at $72^{\circ} \mathrm{C}$ for $60 \mathrm{sec}$ for 35 cycles. Each allele-specific PCR sample $(10 \mu \mathrm{l})$ was mixed with $2 \mu \mathrm{l}$ of loading dye and loaded on a $2 \%$ agarose gel, followed by staining with ethidium bromide.

5-AZA and TSA treatment. Lung cancer cells (5x105/dish) were seeded into $100-\mathrm{mm}$ dishes. One day later, $10 \mu \mathrm{M}$ 5-AZA and $1 \mu \mathrm{M}$ TSA (both from Sigma-Aldrich Japan K.K., Tokyo) were added in RPMI-1640 containing 10\% FCS. After 3 days of treatment, the total RNA and the protein were extracted from these cells. The effect of these drugs was analyzed by Western blot analysis and real-time RT-PCR using the above-mentioned methods.

Drugs and growth-inhibition assay. Gefitinib was provided by AstraZeneca and dissolved in dimethyl sulfoxide (DMSO) for in vitro studies. We used the colorimetric MTT assay to examine the activity of TSA and gefitinib against PC9, PC9/f9 and PC9/f14 cells as previously reported (12.26). Cell suspensions $\left(200 \mu 1,10^{5}\right.$ cells $\left./ \mathrm{ml}\right)$ were seeded into 96-well microtiter plates and $10 \mu \mathrm{l}$ of drug solution added, at various concentrations (TSA, 0-50 $\mu \mathrm{M}$; gefitinib, 0-50 $\mu \mathrm{M}$ ).

After incubation for $72 \mathrm{~h}$ at $37^{\circ} \mathrm{C}, 20 \mu \mathrm{l}$ of MTT solution [5 $\mathrm{mg} / \mathrm{ml}$ in phosphate-buffered saline (PBS)] was added to each well and incubation then continued for a further $4 \mathrm{~h}$ at $37^{\circ} \mathrm{C}$. In addition, the effect of combination treatment with TSA and gefitinib at the concentrations indicated (TSA, $0.5 \mu \mathrm{M}$; gefitinib $1.0 \mu \mathrm{M}$ ) was analysed in the abovementioned assay.

Each experiment was repeated at least three times. Statistical analysis was performed using the student's t-test to compare the cells treated with the combinations to the cells treated with either drug alone. A $p<0.05$ was considered statistically significant.

\section{Results}

PTEN mRNA and protein expression in lung cancer cell lines. We analyzed the expression levels of PTEN protein in a panel of 25 lung cancer cell lines, as well as BET2A cells (Fig. 1). Six of the 25 cell lines (24\%) displayed low levels of PTEN protein; PC9/f9, PC9/f14, PC14, PC10, QG56 and N231 cells. BET2A cells expressed PTEN protein at a moderate level. The gefitinib-sensitive cell line, PC9, demonstrated moderate expression of PTEN protein, whereas there was minimal or absent expression of PTEN protein in the PC9/f9 and PC9/f14 cell lines, both of which are gefitinib-resistant derivatives of PC9 cells (12).

In this subgroup of six cell lines the expression levels of PTEN mRNA, as determined by real-time RT-PCR analysis, correlated well with PTEN protein expression, all six displayed reduced expression when compared to PC9 and BET2A cells (Fig. 2). 


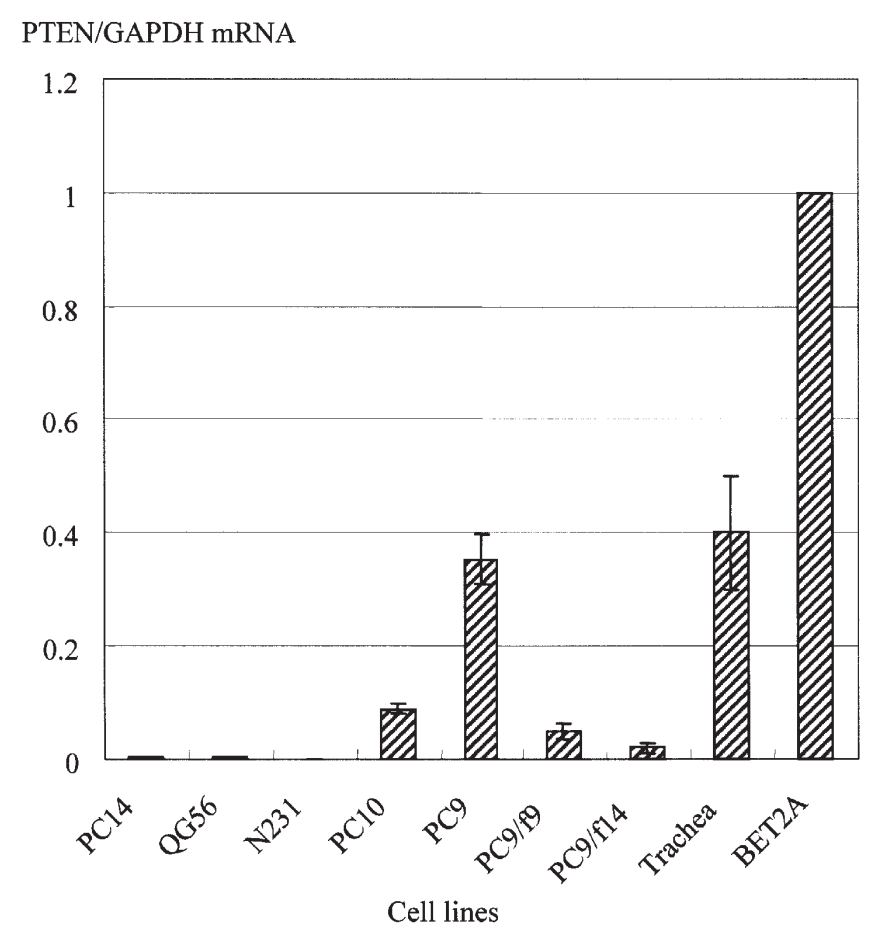

Figure 2. Real-time RT-PCR analysis of PTEN mRNA expression. The level of PTEN mRNA, as determined by real-time RT-PCR analysis, was expressed as the ratio of PTEN to glyceraldehydes-3-phosphate dehydrogenase $(G A P D H)$ mRNA. Each sample was measured three times. The bar chart was prepared with the StatView program (SAS Institute Inc., Cary, NC), with the error bars referring to variation in expression levels between independent measurements.
PTEN mutational analysis via PCR-SSCP and DNA sequencing. Homozygous deletion of the PTEN gene is reported to frequently occur in lung cancer $(13,27,28)$. Accordingly, we performed PTEN mutational analysis, via PCR-SSCP and DNA sequencing, on genomic DNA extracted from the entire panel of lung cancer cell lines, as well as the BET2A cells. Homozygous deletions of the PTEN gene were detected in two of the six cell lines that displayed low PTEN protein expression. Both of these cell lines, QG56 and N231, had homozygous deletions in the exon 1 region of the PTEN gene. No other mutations in the PTEN gene were found in the remainder of samples (Fig. 3).

Sodium bisulfite modification and methylation-specific PCR (MSP). To determine the methylation status of the PTEN gene in our series of lung cancer cell lines, MSP analysis was performed on the six lung cancer cell lines with low PTEN protein expression, as well as BET2A cells and the PC9 cell line (both of which display moderate PTEN expression). The PC10 and PC14 cell lines showed evidence of hyper-methylation in the promoter region of the PTEN gene (Fig. 4). Crucially, expression of both PTEN mRNA and protein was increased in PC10 and PC14 cells, following treatment with 5-AZA (Fig. 5).

Histone deacetylation analysis by TSA treatment. To further understand the contribution of epigenetic mechanisms to regulation of PTEN expression, we treated the subset of six lung cancer cell lines displaying low PTEN protein expression, as well as PC9 cells, with $1 \mu \mathrm{M}$ TSA for 3 days. Following

\section{Electrophoresis exon1}

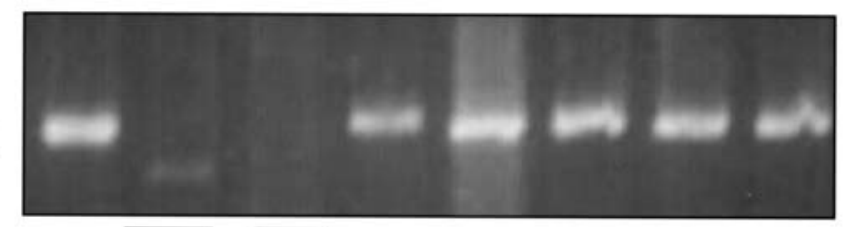

BET2A QG56 N231 PC10 PC9 PC9/f9 PC9/f14 PC14

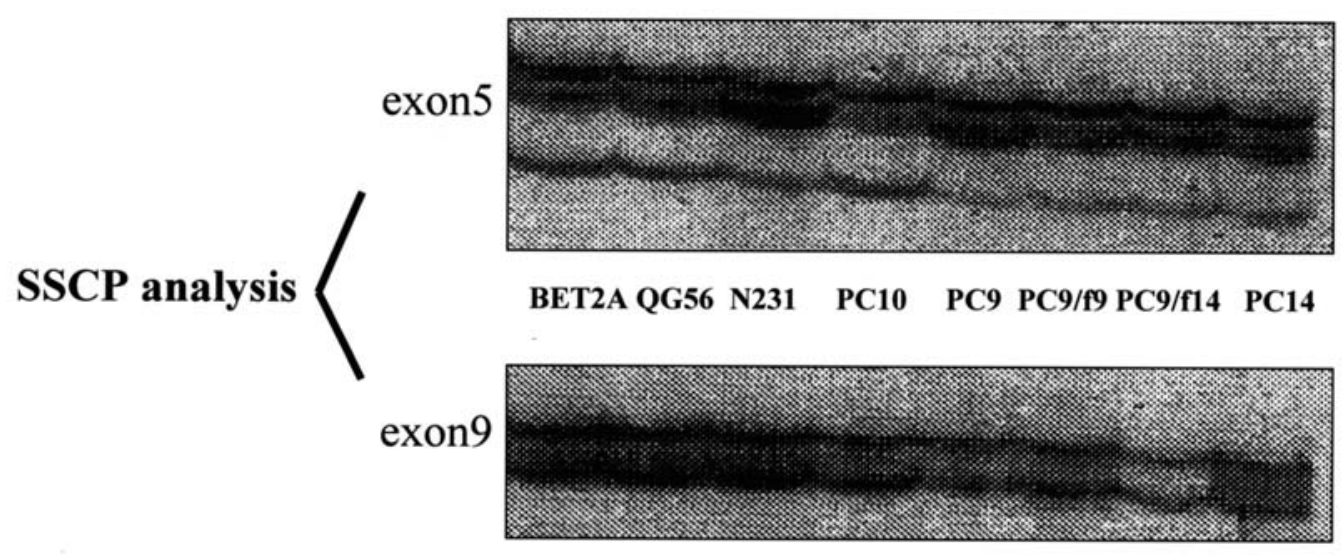

BET2A QG56 N231 PC10 PC9 PC9/f9 PC9/f14 PC14

Figure 3. Mutational analysis of the PTEN gene. The genetic status of the PTEN gene across the 25 lung cancer cell lines, as well as BET2A cells, was assessed via PCR-SSCP analysis and DNA sequencing. The status of exons 1, 5 and 9 regions of the PTEN gene is shown. QG56 and N231 had homozygous deletions in the exon 1 region of the PTEN gene. 

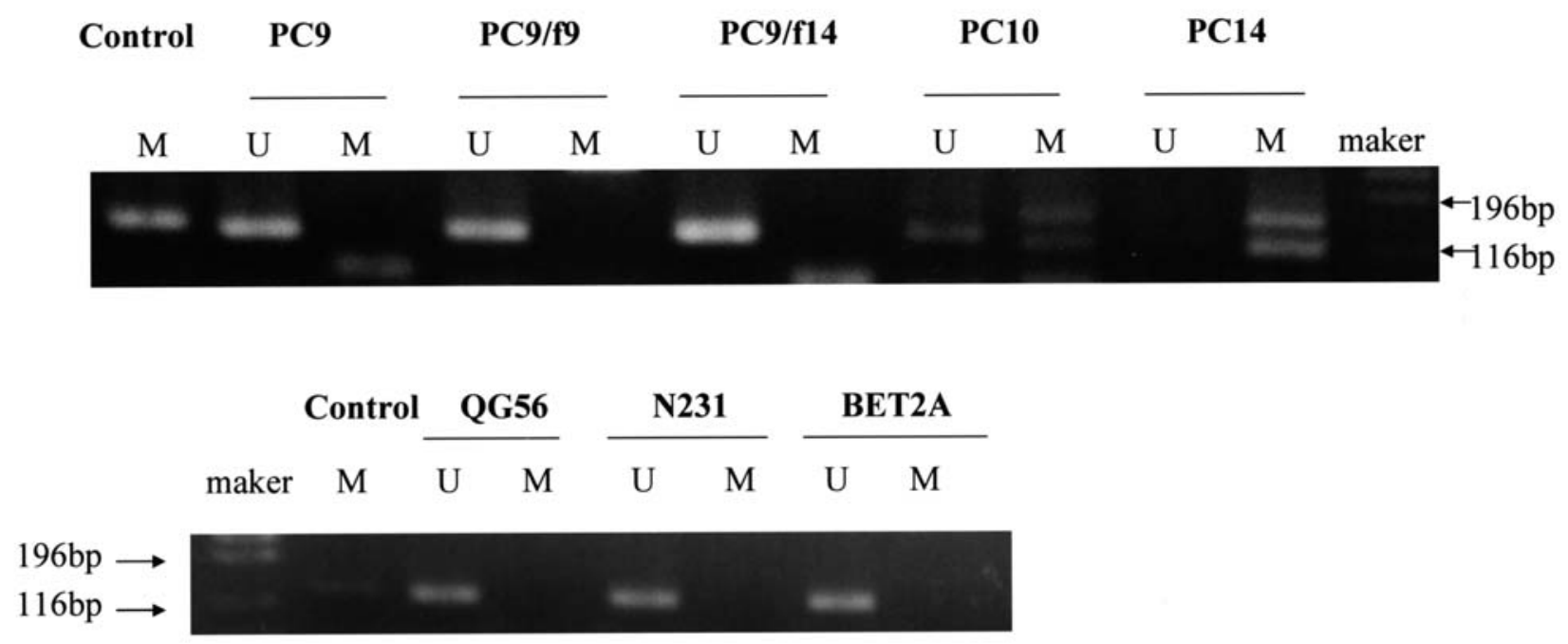

Figure 4. Methylation of the PTEN promoter region. MSP analysis was used to determine the methylation status of the promoter region of the PTEN gene (24). Control, positive control; $\mathrm{M}$, amplified product with primers recognizing methylated sequence; U, amplified product with primers recognizing unmethylated sequence.

(A)
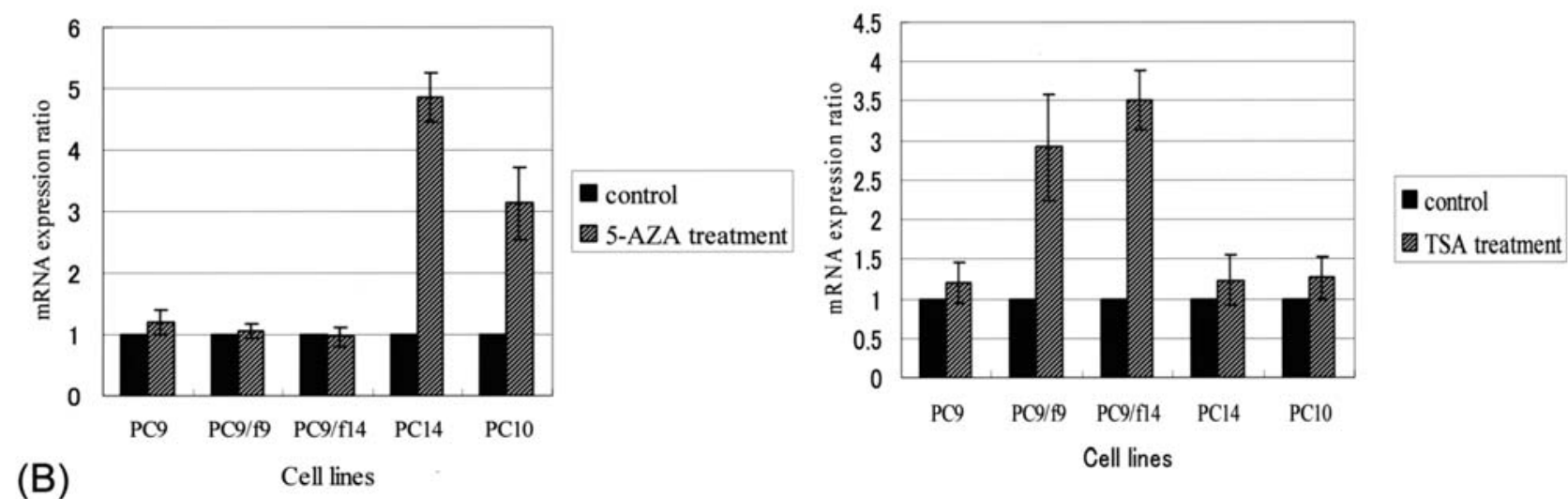

(B)

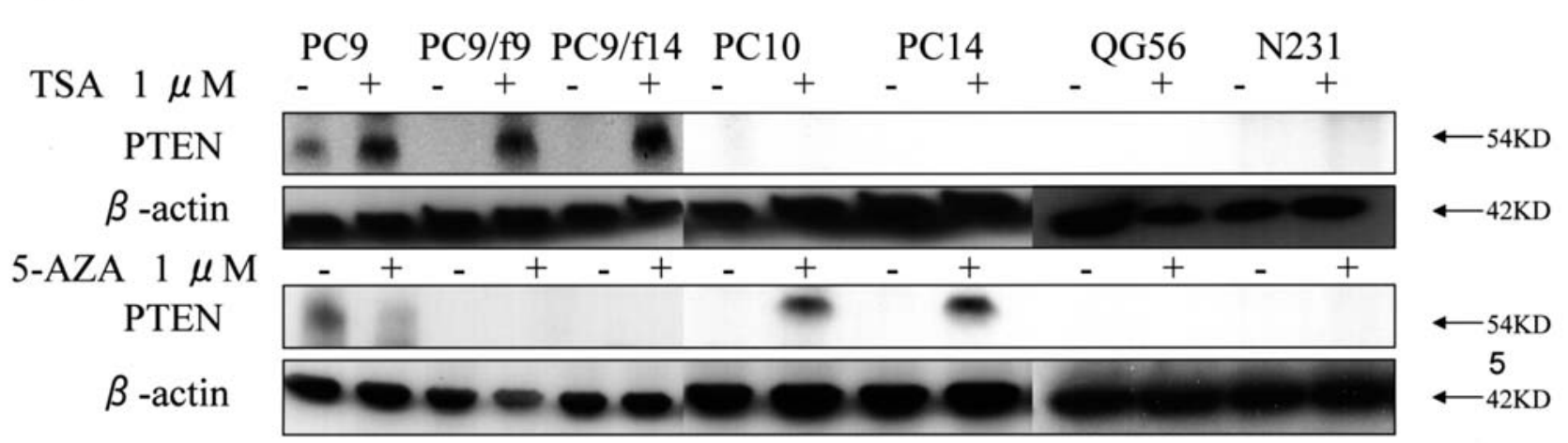

Figure 5. Recovery of PTEN expression via use of epigenetic modifiers. PTEN expression was measured in a subset of lung cancer cell lines, plus/minus treatment with 5-AZA or TSA, via (A) real-time RT-PCR or (B) Western blot analysis. (A) mRNA expression relativity (post-treatment/pre-treatment) was measured three times. Bar, \pm SD.

TSA treatment, the expression of PTEN mRNA and protein in PC9/f9 and PC9/f14 cells had recovered to the same level as native PC9 cells. However, no increase in expression of PTEN was seen in the other four cell lines (PC10, PC14, QG56 and N231) following TSA treatment (Fig. 5).
Drugs and growth-inhibition assay. We have previously reported that two subpopulations of the PC9 cell line, PC9/f9 and PC9/f14, show natural resistance to gefitinib (12). Combination treatment with gefitinib $(1 \mu \mathrm{M})$ and TSA $(0.5 \mu \mathrm{M})$ induced significant growth inhibition in PC9/f9 and PC9/f14 


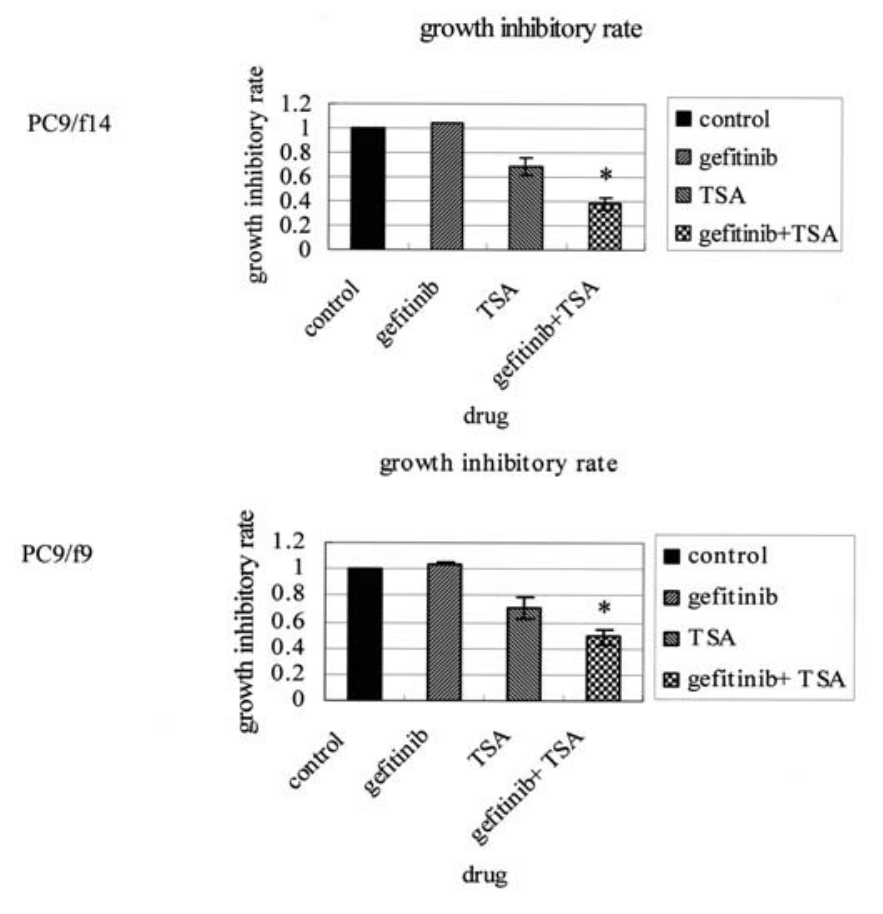

Figure 6. Effect of gefitinib, Trichostatin A and the combination of both on cell growth. The activity of combinations of TSA $(0.5 \mu \mathrm{M})$ and gefitinib $(1 \mu \mathrm{M})$ against PC9/f9 and PC9/f14 gefitinib resistant cells was determined using the colorimetric MTT assay following $72 \mathrm{~h}$ of treatment. Each experiment was repeated at least three times. Statistical analysis was performed using the Student's t-test to compare the cells treated with the combinations to the cells treated with either drug alone. A p $<0.05$ was considered statistically significant. Bar, \pm SD.

cells compared with control and treatment with either agents $(\mathrm{p}<0.05)$ (Fig. 6).

\section{Discussion}

Loss of PTEN function increases the cellular concentration of PIP-3, which in turn leads to Akt hyperactivation, suggesting that the tumor suppressor function of PTEN is exerted through the negative regulation of the PI3K/Akt cell pathways (4). According to recent reports, loss of PTEN is associated with poor prognosis for patients with lung cancer (7-9), as well as resistance to many anti-cancer agents, including gefitinib (10-12). To understand the mechanisms leading to loss of PTEN protein expression in lung cancer, we performed mutational and epigenetic analyses of the PTEN gene. In this study, 6 out of 25 (24\%) lung cancer cell lines displayed low PTEN expression. We detected homozygous deletions of the PTEN gene in two of these six cell lines that had low PTEN expression. Both of these cell lines, QG56 and N231, displayed homozygous deletion in the exon 1 region of the PTEN gene. Absence of PTEN expression in lung cancer cell lines with homozygous deletions of the gene have also been reported by Kohno et al (5\% of cells) and Forgacs et al (4\% of cells) $(13,15)$. DNA sequence analysis of the PTEN gene showed no other mutations in the remaining lung cancer cell lines (15). Two other studies have demonstrated an absence of PTEN mutations in lung cancer cell lines $(14,16)$.

Soria et al reported that the frequency of PTEN inactivation (24\%) at the protein level in 125 NSCLC tissues, as determined by immunohistochemistry, was higher than the rate $(23 \%)$ of PTEN genetic alteration (17). In our study, the expression levels of PTEN mRNA in the subset of six cell lines were reduced compared to the PC9 cell line and BET2A cells, this was consistent with the results obtained at the protein level. Another possible mechanism of PTEN inactivation may be epigenetic inactivation of the gene through hypermethylation $(17,29)$ and/or histone deacetylation. In our study four of the six cell lines with minimal PTEN expression showed evidence of epigenetic alterations. Two of these cell lines (PC10 and PC14) displayed hypermethylation in the promoter region of the PTEN gene, as determined by MSP analysis. Khan et al reported that $60 \%$ of invasive breast cancer samples with PTEN inactivation showed hypermethylation in the promoter region of the PTEN gene (30). In our study the expression levels of PTEN mRNA and protein actually recovered in PC10 and PC14 cells, following treatment with the demethylating agent 5-AZA. Another key epigenetic event is histone deacetylation. When the histones are deacetylated, the chromatin is more compact and transcriptionally inactive (31). In our study, expression of PTEN mRNA and protein in the gefitinib-resistant PC9/f9 and PC9/f14 cell lines recovered following treatment with the HDAC inhibitor TSA to the level observed in the parental gefitinib-sensitive PC9 cell. Thus, diminished levels of PTEN, a regulator of EGFR pathways, might decrease gefitinib sensitivity, as previously reported (12). HDAC inhibitors, such as TSA, have been demonstrated to inhibit the expression of anti-apoptotic genes (i.e. c-Myc, cyclin D1 and BCL-XL) and increase the transcription of pro-apoptotic genes (p21 waf1/cip1) (32-34). Currently, several hydroxamate-based inhibitors, including TSA, have been shown to selectively inhibit tumor growth in animals at apparently nontoxic doses (35). Recently, SAHA, a hydroxamic acids, has been used clinically for the treatment of cutaneous T-cell lymphoma (35).

Using the growth-inhibition assay, we demonstrated that the combination treatment of gefitinib and TSA at low concentrations induced significant growth inhibition in gefitinib-resistant PC9/f9 and PC9/f14 cells. The important role of the EGFR signaling pathway in some lung cancers and the findings in our recovery study suggest that the combination of the EGFR TKI gefitinib with the demethylating agent 5-AZA and the HDAC inhibitor TSA may be a useful strategy for the treatment of some lung cancers.

\section{Acknowledgements}

IRESSA is a trademark of the AstraZeneca group of companies. This study was supported in part by a Grant-in-Aid from the Ministry of Education, Culture, Sports, Science, and Technology of Japan and Japan Society for the Promotion of Science.

\section{References}

1. Parkin DM, Bray F, Ferlay and Pisani P: Global cancer statics. CA Cancer J Clin 55: 74-108, 2002.

2. Li J, Yen C, Liaw D, Podsypanina K, Bose S and Wang SI: PTEN, a putative protein tyrosine phosphatase gene mutated in human brain, breast, and prostate cancer. Science 275: 1943-1947, 1997.

3. Maehama T and Dixon JE: The tumor suppressor, PTEN/ MMAC1, dephosphorylates the lipid second messenger, phosphatidylinositol 3,4,5-trisphosphate. J Biol Chem 273: 13375-13378, 1998 . 
4. Di Cristofano A and Pandolfi PP: The multiple roles of PTEN in tumor suppression. Cel 100: 387-390, 2000.

5. Brognard J, Clark AS, Ni Y and Dennis PA: Akt/protein kinase B is constitutively active in non-small cell lung cancer and promotes cellular survival and resistance to chemotherapy and radiation. Cancer Res 61: 3986-3997, 2001.

6. Clark AS, West KA, Blumbrg PM and Dennis PA: Altered protein kinase $\mathrm{C}$ (PKC) isoforms in non-small cell lung cancer cells: PKC delta promotes cellular survival and chemotherapeutics resistance. Cancer Res 63: 780-786, 2003.

7. Tang JM, He QY, Guo RX and Chang XJ: Phosphorylated Akt overexpression and loss of PTEN expression in non-small cell lung cancer confer poor prognosis. Lung Cancer 51: 181-191, 2006.

8. Bepler G, Sharma S, Cantor A, Gautam A, Haura E, Simon G, Sharma A, Sommers E and Robinson L: RPM1 and PTEN as prognosistic parameters for over all and disease-free survival in patients with non-small-cell lung cancer. J Clin Oncol 22: 1878-1885, 2004

9. Sui L, Dong Y, Watanabe Y, Yamaguchi F, Sugimoto K and Tokuda M: Alteration and clinical relevance of PTEN expression and its correlation with survivin expression in epithelial ovarian tumors. Oncol Rep 15: 773-778, 2006.

10. She QB, Solit D, Basso A and Moasser MM: Resistance to gefitinib in PTEN-null HER-overexpressing tumor cells can be overcome through restoration of PTEN function or pharmacologic modulation of constitutive phosphatidylinositol 3kinase/Akt pathway signaling. Clin Cancer Res 9: 4340-4346, 2003.

11. Yan X, Fraser M, Qiu Q and Tsang BK: Over-expression of PTEN sensitizes human ovarian cancer cells to cisplatin-induced apoptosis in a p53-dependent manner. Gynecol Oncol 102: 148-155, 2006.

12. Kokubo Y, Gemma A, Noro R, Seike M, Kataoka K, Matsuda K, Okano T, Minegishi Y, Yoshimura A, Shibuya M and Kudoh S: Reduction of PTEN protein and loss of epidermal growth factor receptor gene mutation in lung cancer with natural resistance to gefitinib (IRESSA). Br J Cancer 92: 1711-1719, 2005.

13. Kohno T, Takahashi M, Manda R and Yokota J: Inactivation of the PTEN/MMAC1/TEP1 gene in human lung cancers. Genes Chromosomes Cancer 22: 152-156, 1998.

14. Yokomizo A, Tindall DJ, Drabkin H, Gemmill R, Franklin W, Yang P, Sugio K, Smith DI and Liu W: PTEN/MMAC1 mutations identified in small cell, but not in non-small cell lung cancers. Oncogene 17: 475-479, 1998.

15. Forgacs E, Biesterveld EJ, Sekido Y, Fong K, Muneer S, Wistuba II, Milchgrub S, Brezinschek R, Virmani A, Gazdar AF and Minna JD: Mutation analysis of the PTEN/MMACl gene in lung cancer. Oncogene 17: 1557-1565, 1998.

16. Hosoya Y, Gemma A, Seike M, Kurimoto F, Uematsu K, Hibino S, Yoshimura A, Shibuya M and Kudoh S. Alteration of the PTEN/MMAC1 gene locus in primary lung cancer with distant metastasis. Lung Cancer 25: 87-93, 1999.

17. Soria JC, Lee HY, Lee JI, Wang L, Issa JP, Kemp BL, Liu DD, Kurie JM, Mao L and Khuri FR: Lack of PTEN expression in non-small cell lung cancer could be related to promoter methylation. Clin Cancer Res 8: 1178-1184, 2002.

18. Gemma A, Hagiwara K, Vincent F, Ke Y, Hancock AR, Nagashima M, Bennett WP and Harris CC: hSmad5 gene, a human hSmad family member: its full length cDNA, genomic structure, promoter region and mutation analysis in human tumors. Oncogene 16: 951-956, 1998.
19. Gemma A, Takenoshita S, Hagiwara K, Okamoto A, Spillare EA, McMemamin MG, Hussain SP, Forrester K, Zariwala M, Xiong Y and Harris CC: Molecular analysis of the cyclin-dependent kinase inhibitor genes p15INK4b/MTS2, p16INK4/MTS1, p18 and p19 in human cancer cell lines. Int J Cancer 68: 605-611, 1996.

20. Takenaka K, Shibuya M, Takeda Y, Hibino S, Gemma A, Ono $\mathrm{Y}$ and Kudoh S: Altered expression and function of $\beta 1$ integrins in a highly metastatic human lung adenocarcinoma cell line. Int J Oncol 17: 1187-1194, 2000.

21. Gemma A, Takenaka K, Hosoya Y, Matuda K, Seike M, Kurimoto F, Ono Y, Uematsu K, Takeda Y, Hibino S, Yoshimura A, Shibuya M and Kudoh S: Altered expression of several genes in highly metastatic subpopulations of a human pulmonary adenocarcinoma cell line. Eur J Cancer 37: 1554-1561, 2001.

22. Gemma A, Hagiwara K, Ke Y, Burke LM, Kahn MA, Nagashima M, Bennet WP and Harris CC: FHIT mutations in human primary gastric cancer. Cancer Res 57: 1453-1457, 1997.

23. Gibson UE, Heid CA and Williams PM: A novel method for real-time quantitative RT-PCR. Genome Res 6: 995-1001, 1996.

24. Herman JG, Graff JR, Myohanen S, Nelkin BD and Baylin SB Methylation-specific PCR: a novel PCR assay for methylation status of CpG islands. Proc Natl Acad Sci USA 93: 9821-9826, 1996.

25. Zysmann MA, Chapman WB and Bapat B: Considerations when analyzing the methylation status of PTEN tumor suppressor gene. Am J Pathol 160: 795-800, 2002.

26. Mosmann T: Rapid colorimetric assay for cellular growth and survival: application to proliferation and cytotoxicity assays. J Immunol Methods 65: 55-63, 1983.

27. Ali IU, Schriml LM and Dean M: Mutational spectra of PTEN/ MMAC1 gene: a tumor suppressor with lipid phosphatase activity. J Natl Cancer Inst 91: 1922-1932, 1999.

28. Vivanco I and Sawyers CL: The phosphatidylinositol 3-kinase AKT pathway in human cancer. Nat Rev Cancer 2: 489-501, 2002 .

29. Salvessen HB, MacDonald N, Ryan A, Jacobs IJ, Lynch ED, Akslen LA and Das S: PTEN methylation is associated with advanced stage and microsatellite instability in endometrial carcinoma. Int J Cancer 91: 22-26, 2001.

30. Khan S, Kumagai T, Vora J, Bose N, Sehgal I, Koeffler PH and Bose S: PTEN promoter is methylated in a proportion of invasive breast cancers. Int J Cancer 112: 407-410, 2004.

31. Lin HY, Chen CS, Lin SP, Weng JR and Chen CS: Targeting histone deacetylase in cancer therapy. Med Res Rev 4: 397-413, 2006.

32. Van Lint C, Emilliani S and Verdin E: The expression of a small fraction of cellular genes is changed in response to histone hyperacetyaltion. Gene Expr 5: 245-253, 1996.

33. Eickhoff B, Ruller S, Lae T, Ohler G, Schlaak M and van der Bosch J: Trichostatin A modulates expression of $\mathrm{p} 21^{\text {waf } 1 / \text { cip } 1 \text {, }}$ BCL-XL, ID1, ID2, ID3, CRAB2, GATA-2, hsp86 and TFIID/ TAFII31 mRNA in human lung adenocarcinma. Biol Chem 381: 107-112, 2000

34. Chung DH, Zhang F, Chen F, MclaughlinWP and Liungman M: Butyrate attenuates BCLX(L) expression in human fibroblasts and acts in synergy with ionizing radiation to induce apoptosis Radiat Res 149: 187-194. 1998.

35. Marks PA, Richon VM, Miller T and Kelly WK: Histone deacetylase inhibitors. Adv Cancer Res 91: 137-168, 2004. 